\title{
Desain Kaki Palsu untuk Membantu Aktivitas Berjalan pada Tuna Daksa Transtibial dengan Menggunakan Rapid Prototyping dan Reverse Engineering
}

\author{
Agung Dwi Junianto dan Djoko Kuswanto \\ Departemen Desain Produk Industri, Fakultas Arsisektur Desain dan Perencanaan, Institut Teknologi Sepuluh \\ Nopember (ITS) \\ e-mail: crewol@prodes.its.ac.id
}

\begin{abstract}
Abstrak-Dari keseluruhan jumlah penduduk di Indonesia dengan disabilitas mencapai 2.126 .000 jiwa, dengan total jumlah tuna daksa 717.312 dan Tuna Daksa dengan grahita berjumlah 149.458 jiwa, sama dengan menyumbang $47.4 \%$ dari total keseluruhan jumlah difabel. Hidup sebagai penyandang cacat di tengah-tengah rmasyarakat membuat mereka merasa terisolasi dalam kehidupan sosial dan memiliki kebutuhan yang tak terpenuhi dalam kaitannya dengan keuangan, pekerjaan dan kegiatan sosial, sementara. Dengan keadaan demikian, maka dibutuhkan alat bantu gerak untuk penyandang tuna daksa kaki, khususunya jenis amputasi bagian bawah lutut. Dengan proses pembuatan yang konvensional, harga kaki palsu masih terbilang mahal bagi golongan menengah ke bawah. Karena itu, metode rapid prototyping menjadi alternatif proses pembuatan modern untuk menekan biaya. Metode dimulai dengan mengambil data primer, shadowing, dan deep interview. Konsep yang digunakan untuk kaki palsu ini adalah curvy agar kaki palsu lebih terlihat seperti kaki manusia pada umumnya guna meningkatkan rasa percaya diri pengguna. Selain itu, flexi foot untuk memberikan mekanisme pada jari jari agar kaki ketika melangkah, gerakan toe off mampu memberikan efek yang sama seperti manusia berjalan pada umumnya.
\end{abstract}

Kata Kunci-amputate, leg, prosthetic, Rapid Prtotyping.

\section{PENDAHULUAN}

$\mathrm{D}$ ARI keseluruhan jumlah penduduk di Indonesia dengan disabilitas mencapai 2.126 .000 jiwa, dengan total jumlah tuna daksa 717.312 dan Tuna Daksa dengan grahita berjumlah 149.458 jiwa, sama dengan menyumbang $47.4 \%$ dari total keseluruhan jumlah [1].

Tiap pasien amputasi mengalami shock dalam menerima kehilangan salah satu anggota tubuhnya, dengan keadaan seperti itu para pasien sangat membutuhkan dukungan secara fisik atupun psikis, dikarenakan pasien amputasi memiliki kebutuhan seperti ekonomi, dan kehidupan sosial yang tak terpenuhi [2], sedangkan dukungan secara fisik bisa diwujudkan melalui alat bantu palsu (prosthetic) dalam jurnal ini prosthetic leg.

Pengembangan prosthetic leg di Indonesia sendiri tertinggal jauh dengan negara-negara lain. prosthetic leg yang banyak di pasaran Indonesia lebih mengacu pada bentukan cosmetic, karena bentuk yang menyerupai kaki asli lebih memuaskan bagi pasien tuna daksa [3] sehingga secara fungsi belum banyak meng cover beberapa foot abilities, seperti dorsiflexion dan plantar flexion. Selain dari fungsi, metode pembuatan prosthetic leg di Indonesia juga masih menggunakan cara cara konvensional meskipun sudah banyak teknologi canggih yang masuk di Indonesia seperti printer 3d. Proses pembuatan prosthetic leg degan printer $3 \mathrm{~d}$ dan reverse engineering memangkas banyak step dibanding pembuatan konvensional.
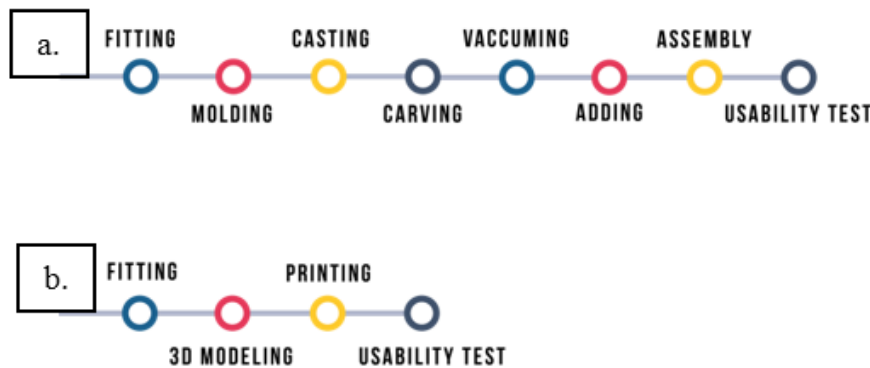

Gambar 1. Step Pembuatan Konvensional (a) dan 3D Printing (b).

\section{METODE PENELITIAN}

A. Bahan dan Alat

1. Filamen ABS dan PLA $1.75 \mathrm{~mm}$

2. Pipa Alumunium $\varnothing 31.75 \mathrm{~mm}$

3. Spring $\varnothing 18 \mathrm{~mm}, \quad l=33 \mathrm{~mm}$

4. Busa Hati tebal $5 \mathrm{~mm}$

5. Mesin Printer 3D Wanhao D4S

6. 3D Scanner EinscanPro.

\section{B. Tahap Pengumpulan Data}

Pengumpulan data diperoleh dari hasil interview user, deep interview dengan expert, dan shadowing, serta pengolahan studi pustaka. Data-data tersebut meliputi:

\section{1) Data Primer}

Interview user berupa ukuran ukuran yang menjadi standart of procedure untuk mengukur pasien tuna daksa kaki, deep interview mengenai pembuatan kaki palsu dengan expert yang menangani bidang prosthetic pada beberapa Rumah Sakit [4].

2) Data sekunder

Studi literatur yang didapat melalui jurnal online yang berkaitan dengan pembahasan dalam jurnal ini.

\section{Tahap Studi dan Analisis}

Studi dan Analisis digunakan untuk memetakan kebutuhan pasien terhadap kaki palsu, serta teknis yang terkait dengan kaki palsu. Beberapa studi dan analisis sebagai berikut 


\section{1) StudiAktivitas}

Studi aktivitas dilakukan untuk mendapatkan data dari pasien tuna daksa, untuk mengetahui keseharian yang seperti apa yang dilakukan pasien sehingga mampu di cover lebih baik dengan kaki palsu rapid prototyping ini.

2) Studi Ergonomi

Bertujuan untuk mengetahui dimana bagian titik kritis yang tidak diperbolehkan melakukan contact langsung dengan material kaki palsu, serta mengetahui tumpuan yang tepat, agar bagian socket tidak mudah lepas dari puntung kaki pasien.

\section{3) Analisis Pasar}

Analisis pasar dilakukan untuk mengkomparasi existing yang ada di pasaran luar negeri maupun dalam negri dan juga melihat kelebihan fitur fitur tiap roduknya.

4) Analisis Material

Untuk mengetahui jenis material struktur (pylon pada kaki palsu) yang sesuai dengan kebutuhan pasien tuna daksa, serta proses produksi.

\section{5) Analisis Gait Cycle}

Analisis dilakukan untuk mengetahui sudut sudut kritis ketika kaki digunakan untuk berjalan guna menjadi data acuan pembuatan mekanisme pada kaki palsu.

\section{Batasan Masalah}

Batasan masalah dalam detail perancangan ini yaitu meliputi:

1. Kaki palsu digunakan untuk penyandang tuna daksa untuk pasien bagian bawah lutut.

2. Cost Production $\pm \mathrm{Rp} 3.500 .000$ agar mampu dicover dana dari BPJS.

3. Membuat desain kaki prosthetic tanpa menggunakan mekanis me mekatronik.

4. Fungsi maksimal prosthetics leg menggantikan otot soleus dan Tibialis Anterior.

5. Prosthetics leg ditargetkan kepada orang orang yang penyandang disabilitas karena amputasi, tidak untuk amputasi yang disebabkan penyakit seperti diabetes dan kanker.

6. Pembuatan Prototype body kaki prosthetic dengan menggunakan $3 \mathrm{~d}$ printer.

7. Hanya beberapa komponen dengan menggunkan $3 \mathrm{~d}$ printer.

\section{HASIL PENELITIAN DAN INOVASI PRODUK}

\section{A. Tahap Survey Pasien}

Pada tahap ini bertujuan untuk mengetahui data utama pasienseperti ukuran kaki dan bentuk stump, selain ukuran, aktivitas keseharian pasien juga diamati seperti naik motor ataupun naik turun tangga kecil.

Bentuk Stump pada tiap pasien memiliki ukurang yang personal, untuk mendapatkan data yang bagus harus menggunakan 3d scanner dan diolah menjadi data digital[5].

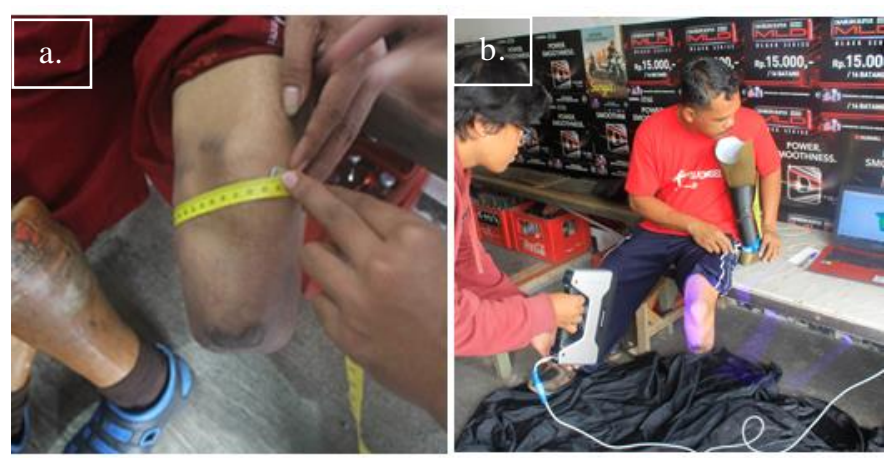

Gambar 2. Pengukuran Manual Kaki Pasien (a) Pengambilan Data dengan Alat 3D Scanner (b).

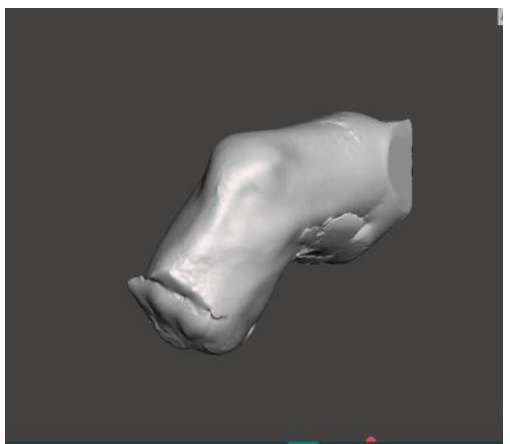

Gambar 3. Bentuk Data Digital Hasil dari 3d Scanning dengan Format File (.Stl)

\section{B. Kesimpulan}

Untuk mendapatkan data ukuran tiap pasien melalui pengukuran manual dan juga melakukan $3 \mathrm{~d}$ scanning khusus untuk bagian stump karena 3d scanner memiliki kepresisian yang tinggi. Dan juga tiap pasien tuna daksa memiliki bentuk puntung yang berbeda-beda

\section{Konsep Desain}

Inovasi pada pengembangan produk kaki palsu untuk pasien tuna daksa bagian transtibial ini dilakukan dengan konsep konsep yang didapat dari hasil observasi user dan juga deep interviewdengan expert. Konsep desain yang disimpulkan adalah:

1) Fit In

Kesesuaian yang harus dimiliki antara socket dengan puntung kaki pasien, dimana hanya bagian lutut dan bagian samping lutut yang dapat dijadikan sebagai tumpuan, hal tersebut dapat dicapai dengan pengambilan bentuk puntung kaki pasien dengan $3 \mathrm{~d}$ scanner.

\section{2) Curvy}

Untuk bentukan kaki palsu yang diminati responden pada umumnya adalah bentuk yang menyerupai kaki asli, kaki sebelah lainnya.

\section{3) Slight Design}

Selain material yang mampu membangun kaki palsu yang ringan, beberapa mekanisme pengganti seperti pada ankle, dan jari jari, memberikan rasa nyaman ketika melangkah [6].

4) Interchangeability

Pada kaki palsu yang dirancang dengan rapid prototyping ini memiliki cover yang mampu di ganti dengan model cover lainnya. 


\section{Sketsa dan AlternatifProsthetic leg}

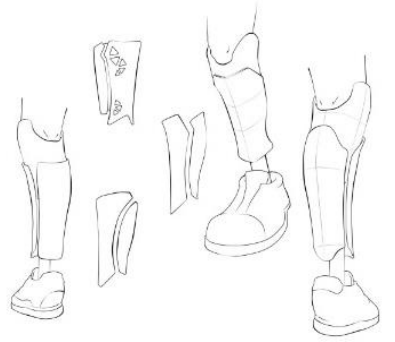

Gambar 4. Sketsa awal desain.
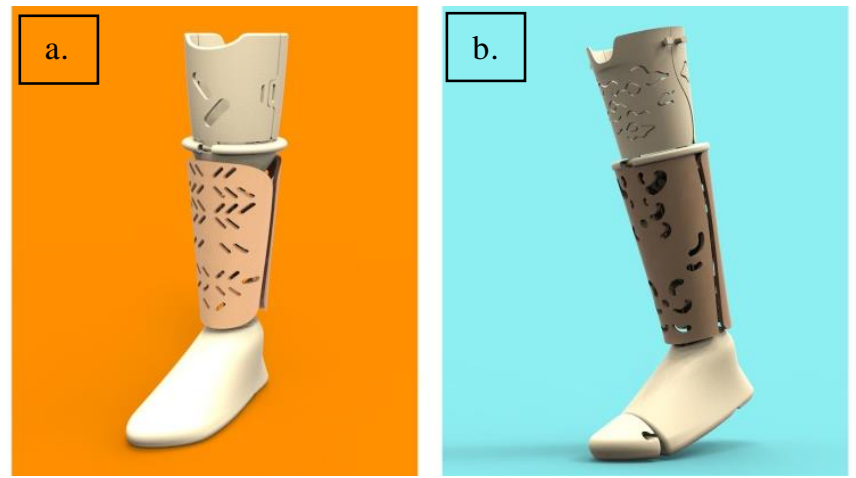

Gambar 5. Alternatif desain 1. Bagian socket bisa dibagi menjadi 2 untuk memudahkan ketika pemasangan (a). Pada bagian kaki terdapat mekanisme sederhana menggunakan bahan flexi (b).
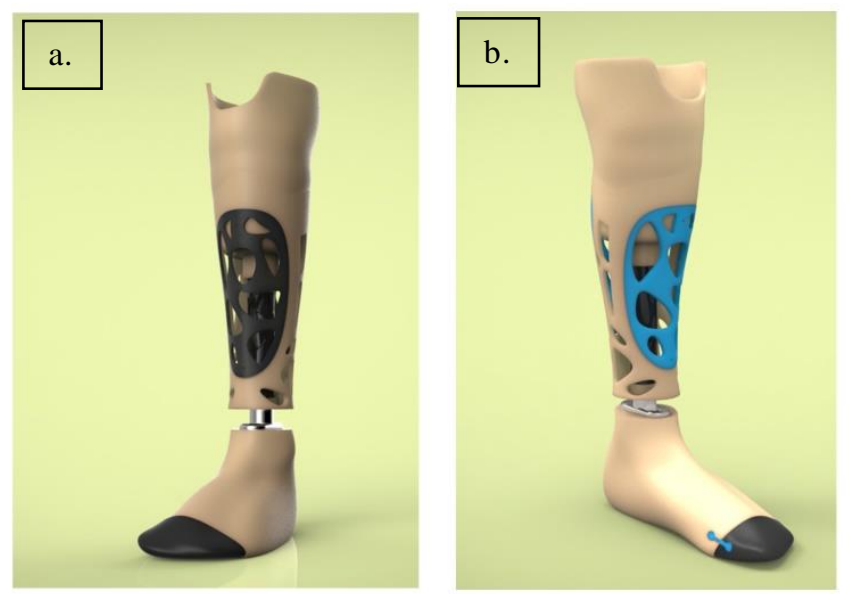

Gambar 6. Alternatif desain 2. Memiliki cover berwarna hitam (a) biru (b)
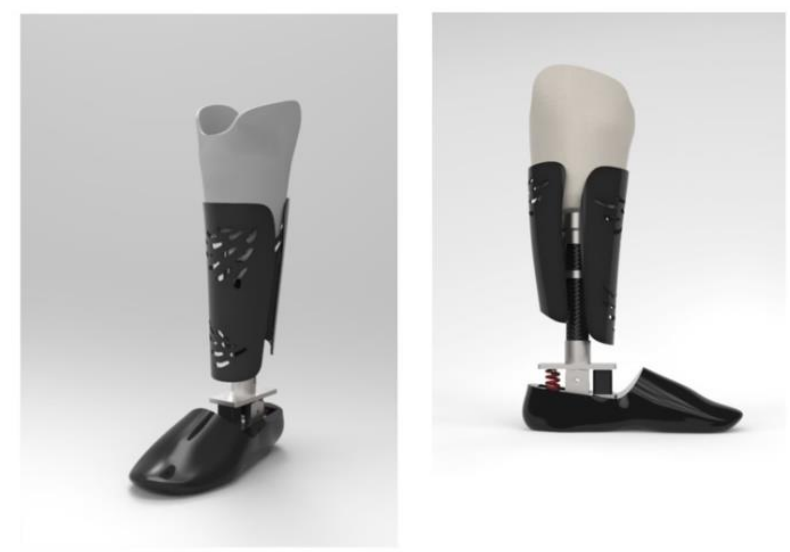

Gambar 7. Alternatif desain 3 dengan cover bagian depan dan belakang.
Dengan kebutuhan utama adalah pasien mampu berjalan dengan gaya jalan yang senormal dan senyaman mungkin, serta fokus menggunakan endoskeletal, dan juga ada nya cover kaki palsu yang mampu dirubah-rubah, alternatif ke-3 diajukan acuan.

\section{E. Desain Final}

Desain Final kaki palsu ini adalah koreksi dari alternatif desain ke-3, dimana bagian kaki sudah memiliki mekanisme pengganti jari jari, serta dumper pada bagian mekanisme ankle sebagai stoper dan juga peredam ketika berjalan.

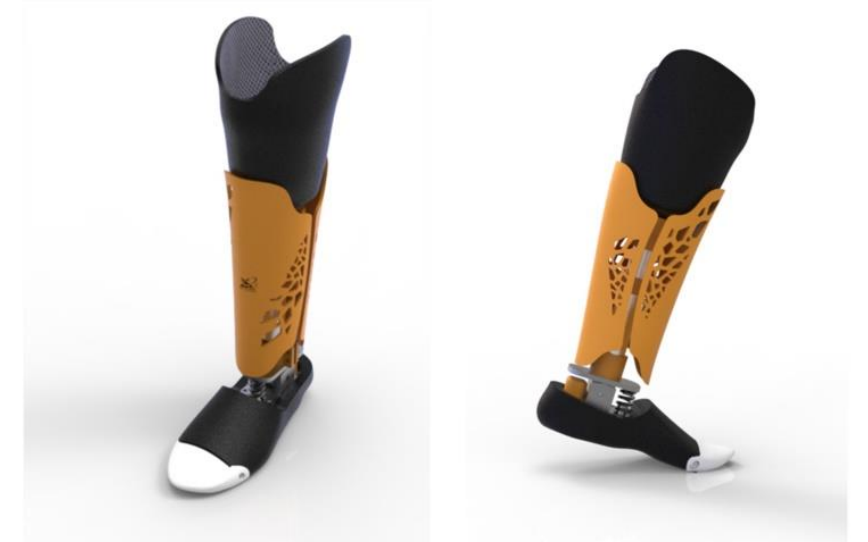

Gambar 8. Final Desain prosthetic leg.

Pada final desain ini juga memiliki varian warna dan juga pattern untuk bagian cover depan dan cover belakang.

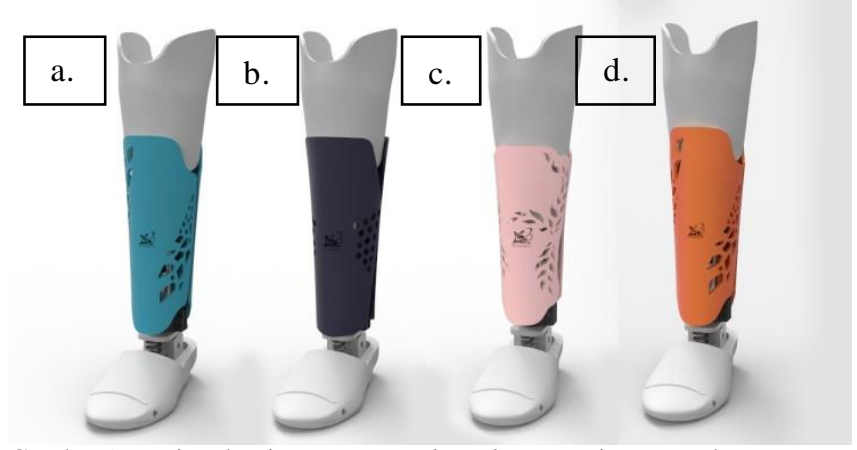

Gambar 9. Varian desain cover prosthetic leg. Desain cover dengan pattern cryptic (a) desain pattern polkadot (b) desain pattern floral (c) desain cover pattern cryptic dengna warna orange (d).

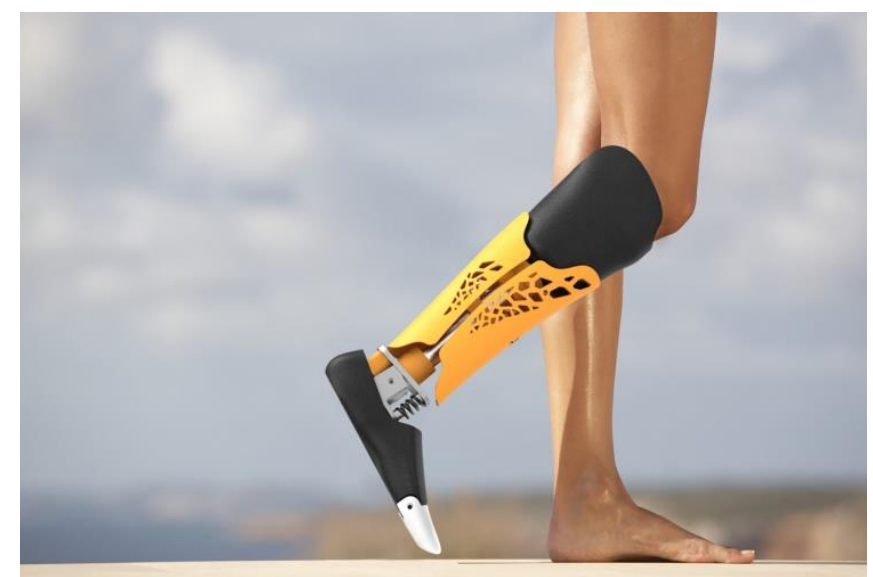

Gambar 10. ilustrasi prosthetic leg ketikadigunakan. 


\section{F. Analisis Material dan Sudut Penting}

Pada perancangan kaki palsu dengan rapid prototyping ini, pada bagian struktur endoskeletal menggunakan beberapa pilihan logam pipa, antara lain pipa carbon, pipa alumunium dan juga pipa titanium. Adapun hasil uji material endoskletal sebagai berikut:

Tabel 1.

Hasil Analisis uji material logam pipa dengan ketebalan dinding $2 \mathrm{~mm}$ pada

\begin{tabular}{clcc}
\multicolumn{4}{c}{ software Fusion360. } \\
\hline \hline Beban & \multicolumn{3}{c}{ Von misses stress pada material (MPa) } \\
$(\mathrm{N})$ & Alumunium7075 & CFRP & Titanium 6Al-4V \\
\hline 800 & 5.4 & 5.579 & 5.489 \\
1200 & 8.165 & 8.369 & 8.233 \\
1800 & 12.25 & 12.55 & 12.35 \\
2000 & 13.61 & 13.95 & 13.72 \\
\hline \hline
\end{tabular}

Tabel 2.

Hasil Analisis uji material logam pipa dengan ketebalan dinding $3 \mathrm{~mm}$ pada software Fusion 360.

\begin{tabular}{llcc}
\hline \hline Beban & \multicolumn{3}{c}{ Von misses stress pada material (MPa) } \\
$(\mathrm{N})$ & Alumunium7075 & CFRP & Titanium 6Al-4V \\
\hline 800 & 3.994 & 4.043 & 3.966 \\
1200 & 5.916 & 6.065 & 5.948 \\
1800 & 8.873 & 9.097 & 8.923 \\
2000 & 9.859 & 10.11 & 9.914 \\
\hline \hline
\end{tabular}

Dari data diatas diketahui jika MPa terendah dimiliki oleh material jenis pipa alumunium 7075 pada ketebalan $2 \mathrm{~mm}$ dan $3 \mathrm{~mm}$, dengan pertimbangan kebutuhan dan lainnya, material pipa alumunium dengan ketebalan $2 \mathrm{~mm}$ sudah cukup untuk dijadikan material struktur endoskeletal.

Untuk menjadikan kaki palsu ini alat bantu gerak yang aman dan nyaman beberapa sudut penting yang terjadi ketika berjalan harus terpenuhi. Berikut hasil anilisis sudut penting ketika manusia berjalan diatas treadmill dengan kecepatan $3 \mathrm{~km} / \mathrm{j}$

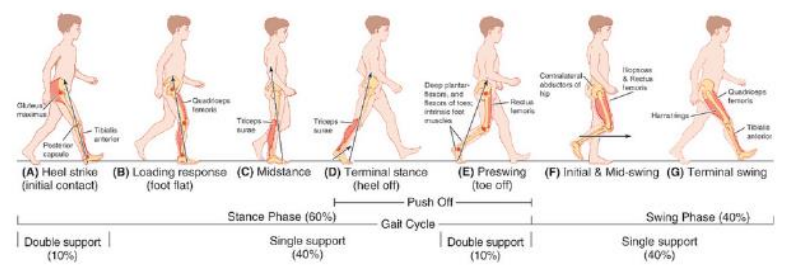

Gambar 11. Gait Cycle normal ketika orang berjalan. Memiliki 7 step: heel strike (a), Loading response (b), Midstance (c), Terminal Stance (d), Preswing (e), initial \& mid swing (f), terminal swing (g) [7].

\section{Plantar, dorsi flexion pada gait cycle}

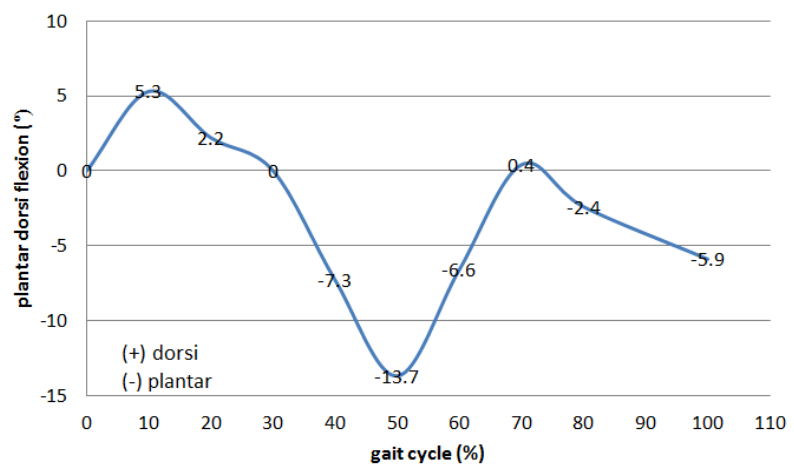

Gambar 12. Grafik gait analisys pada treadmill $3 \mathrm{~km} / \mathrm{j}$.

Dari grafik di atas dapat diperoleh data ketika manusia berjalan dengan kecepatan $3 \mathrm{~km} / \mathrm{h}$, maksimum plantar flexion yang terjadi adalah $\pm 13.7^{\circ}$. Dengan terjadinya plantar flexion sebesar $\pm 13.7^{\circ}$, sudut antara lantai dan telapak kaki yang terjadi adalah $\pm 36.4^{\circ}$, angka ini yang akan menjadi acuan seberapa besar kaki prosthesis dalam desain ini memiliki mekanisme pada bagian pengganti jari jari.

\section{G. Tahap Proses Produksi}

Setelah pembuatan sketsa dan juga $3 \mathrm{~d}$ modeling, hasil $3 \mathrm{~d}$ model dengan format file (.stl) kemudian dicetak pada mesin 3d printing (Wanhao D4S, D6)

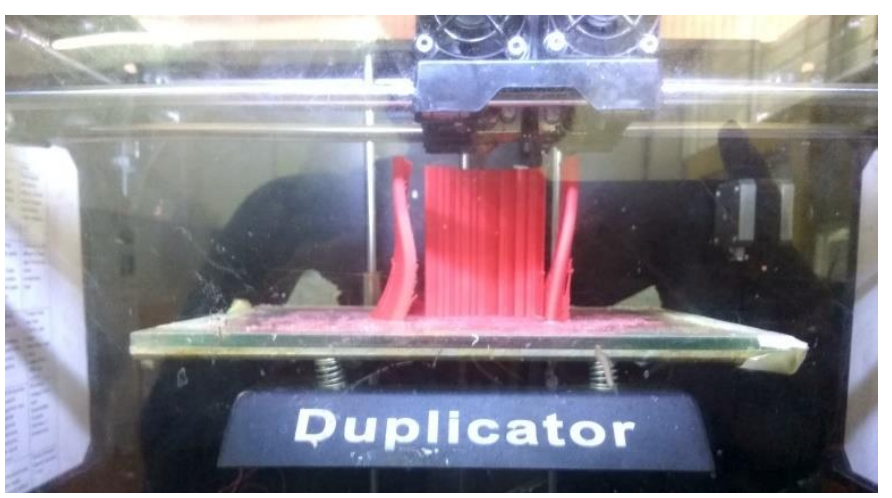

Gambar 12. proses 3d printing bagian kaki palsu.

\section{KESIMPULAN}

Dalam merancang prosthetic leg dengan metode rapid prototyping dan reverse engineering terdapat hal hal yang harus dipertimbangkan, antara lain:

1. Desain kaki palsu sebisa mungkin dibentuk menyerupai kaki asli,seperti lengkungan pada betis, serta bagian foot mampu dikenakan alas kaki.

2. Soft socket tambahan diberikan bahan yang lembut agar puntung kaki pasien tidak mengalam gesekan yang besar.

3. Mekanisme pada kaki palsu yang mampu mengcover gerakan plantardan dorsi flexion. Menggunakan alat yang sederhana seperti spring yang cukup keras untuk meredam benturan.

4. Kaki palsu dibuat dengan material yang ringan dengan tujuan pasien mampu ebrjalan lebih cepat, dan juga tidak mudah lelah.

\section{DAFTAR PUSTAKA}

[1] PDII, "Pusat Data Informasi Nasional." 2012.

[2] L. et Al, Psychosocial adaptation to amputation: The role of sociodemographic variables, disability-related factors and coping strategies.

[3] A. B. Wilson and J. Lower-Limb, "Modular Prostheses A Status Report."

[4] Gatot, "Rumah Sakit Sumber Glagah," 2017.

[5] Y. H. C. et Al., Ankle-Foot Orthosis Made by 3DPrinting Technique and Automated Design Software.

[6] S. J. et Al, "Conceptual Design of an Active Transtibial Prosthesis Based on Expected Joint and Muscle Forces in a Unilateral Transtibial Amputee: A Modelling Study."

[7] V. . et al Rajt'úková, "Biomechanics of Lower Limb Prostheses." 